\title{
BMJ Open Rates of surgical deaths and infections at district hospitals in Malawi and Zambia: a prospective multicentre cohort study
}

\author{
Jakub Gajewski, ${ }^{1}$ Mengyang Zhang (D) , ${ }^{2}$ Leon Bijlmakers (D) , ${ }^{3}$ Chiara Pittalis (D) , ${ }^{1}$ \\ Eric Borgstein, ${ }^{4}$ Gerald Mwapasa, ${ }^{4}$ John Kachimba, ${ }^{5}$ Mweene Cheelo, ${ }^{5}$ \\ Kristen Waterman, ${ }^{2}$ Ruairi Brugha ${ }^{2}$
}

To cite: Gajewski J, Zhang M, Bijlmakers L, et al. Rates of surgical deaths and infections at district hospitals in Malawi and Zambia: a prospective multicentre cohort study. BMJ Open 2021;11:e049126. doi:10.1136/ bmjopen-2021-049126

- Prepublication history for this paper is available online. To view these files, please visit the journal online (http://dx.doi org/10.1136/bmjopen-2021 049126).

Received 19 January 2021 Accepted 06 December 2021

Check for updates

(c) Author(s) (or their employer(s)) 2021. Re-use permitted under CC BY-NC. No commercial re-use. See rights and permissions. Published by BMJ.

For numbered affiliations see end of article.

Correspondence to Dr Jakub Gajewski; jakubgajewski@rcsi.ie

\section{ABSTRACT}

Objective This paper reports perioperative mortality and postoperative infection rates of surgical patients who underwent operations at district-level hospitals in Malawi and Zambia, and the associations of these outcomes with patient characteristics based on routinely available data. Design Prospective cohort study.

Setting Eight government district hospitals in Malawi and nine mission and government district hospitals in Zambia. Outcome measures Perioperative mortality and postoperative infection were used as primary outcome measures in this study. Logistic regression and penalised maximum likelihood logistic regression were used to examine the factors correlated with surgical outcomes.

Results The average perioperative mortality rates were $0.19 \%$ and $0.43 \%$ in Malawi and Zambia, respectively. Penalised maximum likelihood logistic regression showed that age $(\mathrm{OR}=1.046,95 \% \mathrm{Cl} 1.016$ to 1.078$)$ and American Society of Anesthesiologists physical status score II (OR=6.658, 95\% Cl 2.363 to 18.762) were significantly associated with perioperative deaths. General surgery procedures were significantly more likely than obstetrical procedures to result in perioperative deaths $(\mathrm{OR}=3.821,95 \% \mathrm{Cl} 1.226$ to 11.908$)$. The average rates of postoperative infections in Malawi and Zambia were $2.69 \%$ and $2.24 \%$, respectively. Age $(\mathrm{OR}=1.010,95 \% \mathrm{Cl}$ 1.000 to 1.020$)$ and male sex $(\mathrm{OR}=0.407,95 \% \mathrm{Cl} 0.260$ to 0.637 ) were significantly associated with postoperative infections. Additional factors, general procedures ( $\mathrm{OR}=2.319,95 \% \mathrm{Cl} 1.397$ to 3.850 ) and trauma-related procedure $(\mathrm{OR}=5.490,95 \% \mathrm{Cl} 2.632$ to 11.449$)$ were significantly associated with infection rates. There was no significant correlation between surgical outcomes and cadre of lead surgeon (a non-physician clinician or doctor). Conclusion Rates of mortality and postoperative infections in this sample of district-level hospitals in Malawi and Zambia were relatively low, with poorer preoperative physical status as the main predictor of both greater postoperative infection and mortality. The study demonstrates that outcomes of major surgical cases do not depend on the cadre (type) of surgeon performing it, and outcomes can be monitored using routine data, at district level in these countries.

Trial registration number ISRCTN66099597.
Strengths and limitations of this study

First study to report outcomes of district-level surgery using routine data from a large sample of hospitals in a multicountry setting.

- Reporting 18-month data covering 15103 operations from 17 government and mission-district hospitals.

- Routinely collected data used to inform the study.

- Self-reported data could have a potential reporting bias.

- A limitation is the lack of assessment of complications in the long term.

\section{INTRODUCTION}

Providing universal access to safe surgical services is an essential step to reducing the global burden of disease. In sub-Saharan Africa (SSA), inequality in the provision of healthcare services is still high, although geographic accessibility to basic surgery has improved in recent years. ${ }^{1}$ In rural areas, surgical demand remains unmet at district level. ${ }^{2}$ As reported in our earlier studies, ${ }^{34}$ poor access and shortage of surgical care in Malawi and Zambia is widespread among rural populations, aggravated by a lack of surgically trained medical doctors (MD) at district hospitals $(\mathrm{DH})$. As a consequence, task shifting to non-physician clinicians (NPCs) has become a common practice at DHs, with growing evidence of its effectiveness. ${ }^{5-7}$ In developing countries, NPCs are clinical officers who are training separately from MDs, but responsible for medical and surgical tasks usually undertaken by MDs. ${ }^{8}$ In this paper, NPCs are clinical officers in Malawi and medical licentiates (a form of clinical officer with advanced clinical and surgical training) in Zambia with 3 years of basic clinical training, many of whom have received an additional 2-3 years of training 
in surgery. ${ }^{9}$ Evidence from Malawi demonstrated that surgical outcomes for obstetric operations performed by NPCs (measured from the time of surgery until 24 hours postoperation) are comparable to those of MDs. ${ }^{10}$ The aim of this paper is to explore the association between surgical outcomes and patient characteristics and type of provider factors at DHs in Malawi and Zambia.

Perioperative mortality and surgical site infection (SSI) rate are the indicators used to assess surgical safety ${ }^{11}$ in this paper. Surgical mortality rates in SSA are high ${ }^{12-14}$; and SSIs are the most common healthcare-associated infections and a major clinical problem in low and lower middle-income countries. ${ }^{1516}$ SSIs result in longer stays in hospital, leading to higher bed occupancy, increased use of resources and extra expenditure, also raising the costs for patients. SSIs also impair quality of life and productivity. ${ }^{16}{ }^{17}$ A recent systematic literature review estimates the incidence of SSI to be between $6.8 \%$ and $26 \%{ }^{18}$ in SSA. Additional published evidence shows that the risk factors include duration of surgical procedures, wound types, hospital environment, inadequate care practices, late or delayed presentation and comorbidities. ${ }^{15} 1819$ However, there is little published evidence about perioperative mortality and SSIs using routine data, at DHs, which are the main source of surgical care for rural populations.

This paper reports surgical outcomes in Zambia and Malawi during the Clinical Officer Surgical Training in Africa (COST-Africa) research project that took place from 2011 to 2016. In Malawi, COST-Africa supported the in-service BSc in Surgery training programme, through fortnightly visits by surgical specialists to eight government DHs in the Southern and Central Regions. ${ }^{342021}$ In Zambia, nine DHs across five provinces were included and trainees received quarterly supervisory visits by provincial surgical specialists as well as remote supervision by mobile phone. Previous studies showed that in-service training improved surgical productivity and was an effective solution to the provision of surgical services for rural populations. ${ }^{2021}$

\section{METHODS}

\section{Data and sample}

COST-Africa project participants were trained by the project researchers to collect surgical data including postoperative infections and perioperative deaths. Eighteen months of data collected from July 2014 to December 2015 in 17 intervention hospitals (eight hospitals in Malawi, nine hospitals in Zambia) were analysed. The data collection period varied by DHs. The data were extracted from the hard copy of the hospital major operation theatre register on a monthly basis, and all relevant data were entered into an MS Excel template and sent to the research team. For consistency of terminology, raw data were coded by specialist surgeons using a master list and codebook for all surgical conditions and procedures undertaken at DHs. The procedures most commonly performed at district level were assigned individual codes
Table 1 Distribution of major surgical procedures by category (2014-2015) in Malawi and Zambia

\begin{tabular}{|c|c|c|}
\hline Procedure & $\mathbf{n}$ & $\%$ \\
\hline \multicolumn{3}{|l|}{ Obstetric surgery } \\
\hline Caesarean section & 9601 & 81.6 \\
\hline Hysterectomy & 451 & 3.8 \\
\hline Repair of ruptured uterus & 111 & 0.9 \\
\hline Salpingectomy & 141 & 1.2 \\
\hline Bilateral tubal ligation & 1185 & 10.1 \\
\hline Other major procedures & 274 & 2.3 \\
\hline \multicolumn{3}{|l|}{ General surgery } \\
\hline $\begin{array}{l}\text { Inguinal herniotomy/ } \\
\text { herniorrhaphy/hernia repair }\end{array}$ & 913 & 48.5 \\
\hline Other hernia repairs & 159 & 8.5 \\
\hline Hydrocoele excision/repair & 421 & 22.4 \\
\hline Correction of torsion & 17 & 0.9 \\
\hline Prostatectomy & 63 & 3.4 \\
\hline Appendectomy & 45 & 2.4 \\
\hline Gastrointestinal resection & 35 & 1.9 \\
\hline Exploratory laparotomy & 228 & 12.1 \\
\hline \multicolumn{3}{|l|}{ Trauma-related surgery } \\
\hline Amputation/disarticulation & 192 & 37.2 \\
\hline $\begin{array}{l}\text { Reduction/manipulation under } \\
\text { anaesthesia }\end{array}$ & 189 & 36.6 \\
\hline $\begin{array}{l}\text { Other major injury-related } \\
\text { procedures* }\end{array}$ & 135 & 26.2 \\
\hline \multicolumn{3}{|l|}{ Others } \\
\hline Debridement & 680 & 73.1 \\
\hline Skin grafting, dressing & 71 & 7.6 \\
\hline $\begin{array}{l}\text { Other major disability- } \\
\text { preventative procedures* }\end{array}$ & 179 & 19.3 \\
\hline
\end{tabular}

Examples of procedures under the category 'Other major injury-related procedures' were arthrotomy, tendon repair and sequestrectomy; and under the category 'Other major disabilitypreventative procedures' were thyroidectomy, orchidopexy and haemorrhoidectomy.

and organised under three broad categories: obstetric, general and trauma surgery. Generic 'other' codes were used for procedures which were only occasionally performed at district level, and procedures not usually expected to be performed at district level (eg, thyroidectomy performed by visiting specialists). All hospitals were visited during the period of the data collection to ensure that all data on the cases in the major operating theatres (OT) were collected and to cross-check the electronic data sets with the data recorded in the hard copy registers. Major surgical cases were defined as those undertaken in the main OT room, under anaesthesia and requiring at least one overnight postoperative hospital stay (table 1). All such cases with complete tracking information from admission to discharge were selected for the analysis. 


\section{Patient and public involvement}

There is no involvement of patient or public in the design, or conduct, or reporting, or dissemination plans of this research.

\section{Measures}

Surgical procedures for this analysis were grouped as follows: obstetric surgery, general surgery and traumarelated surgery, representing the three most common categories of major procedures undertaken in the study hospitals, and a fourth category of 'other surgical procedures' (table 1).

\section{Dependent variable}

The first dependent variable was a binary one-in-hospital perioperative mortality-defined in this paper as any death which happened during the period from the start of operation up to the time of discharge from the hospital. The second dependent variable was postoperative infection, a binary variable that combined wound infection and pulmonary infection prior to discharge.

\section{Independent variables}

The following independent variables associated with surgical quality were included in the analysis: demographic characteristics of patients, health status, indication for surgery and type or cadre of surgeon (NPC or MD). Patients' demographics, including age and sex, were abstracted from the theatre register. The American Society of Anesthesiologists (ASA) physical status score, abstracted from the theatre register, was used as an assessment of a patient's overall health, defined as a categorical variable-scores I, II and III and higher-where higher score denotes poorer physical status. The operation type (emergency or elective) was included as well. Since the competency of the surgical team might influence surgical quality, two variables of cadre of surgeons were selected: one was whether the surgical team was led by an MD or an NPC; the other was the proportion of MDs on the team.

\section{Analysis methods}

Summary statistics of independent variables by surgical outcomes and country are first presented, followed by the regression results. Logistic regression analysis was used to examine the factors correlated with the two binary surgical outcomes. Robust SEs were clustered at the hospital level to capture within-hospital correlation, and country-fixed characteristics were also included in the regression. The penalised maximum likelihood logistic regression based on the Firth's method was selected to reduce the bias caused by the rarity of events. ${ }^{22} 23$ The ORs of independent variables using two models were shown for comparing association rather than causal interpretation. The statistical analysis was conducted using Stata IC V.13. Significance levels at $\mathrm{p}<0.05$ and $95 \%$ CIs were selected.
RESULTS

\section{Descriptive statistics}

Table 2 summarises the observed data and surgical outcomes by hospital. The mortality rates (mean $=0.0023$, $\mathrm{SD}=0.0481)$ and infection rates (mean $=0.0261$, $\mathrm{SD}=0.1593)$ varied between hospitals. Very few deaths occurred following transfer to a ward $(0.06 \%)$. Nearly $80 \%$ of observations were from Malawi, with none of the DHs in Zambia reporting as many cases of surgery as Mchinji DH which had the lowest in Malawi. Hospitals in Mangochi and Dedza reported the highest number of operations. In Zambia, about half of the cases were reported from Choma District Hospital and Kalene Mission Hospital.

Hospitals in Zambia had a higher average mortality rate than hospitals in Malawi $(0.43 \%$ vs $0.19 \%)$ while Malawian hospitals had a slightly higher average infection rate $(2.69 \%$ vs $2.24 \%$ ) (table 3$)$. Overall, general surgery $(0.53 \%)$ had higher mortality rates than obstetric $(0.18 \%)$ and trauma-related surgery $(0.19 \%)$, whereas traumarelated surgery had higher infection rates $(5.73 \%)$ than the other types of surgery $(2.94 \%$ for general surgery, $2.18 \%$ for obstetric surgery). This was the case in both countries.

Table 4 compares the characteristics of independent categorical and continuous variables with surgical outcomes by country, showing a higher average age of patients who died or contracted an infection after the operation. For patients who died perioperatively, the average proportion of MDs within the operating surgical team was higher. In Zambia, there were more MDs in general so the average share of MDs was higher than in Malawi.

Most patients in the sample were women, and there was no considerable difference by sex between patients who survived and died, and between infected and uninfected patients. The majority of patients were in ASA score I, that is, in healthy physical status, prior to surgery. Obstetric $(78.0 \%)$ and general surgery $(12.5 \%)$ accounted for most operations. In Malawi, $80.5 \%$ of cases were emergency operations. In Zambia, the proportion of elective operations was higher $(58.9 \%)$. Similar to the proportion of MDs within the surgical team, the average proportion of operations led by MD in Zambia was higher than that in Malawi.

Figure 1 shows the distribution of perioperative mortality and postoperative infection rates by sex and age groups, excluding obstetric surgery which is presented separately (figure 2). The average ratios of mortality and infection among women were higher than among men. For women, the share of perioperative mortality was high among women in older age groups, while the share of infection was high among women of childbearing age or older. The majority of deaths occurred among men aged 26-55 years, and the average proportion of infections varied among age groups.

Few deaths were reported in obstetric surgery. Most infections occurred in the childbearing age group. For 
Table 2 Summary of major procedures by hospital in Malawi and Zambia

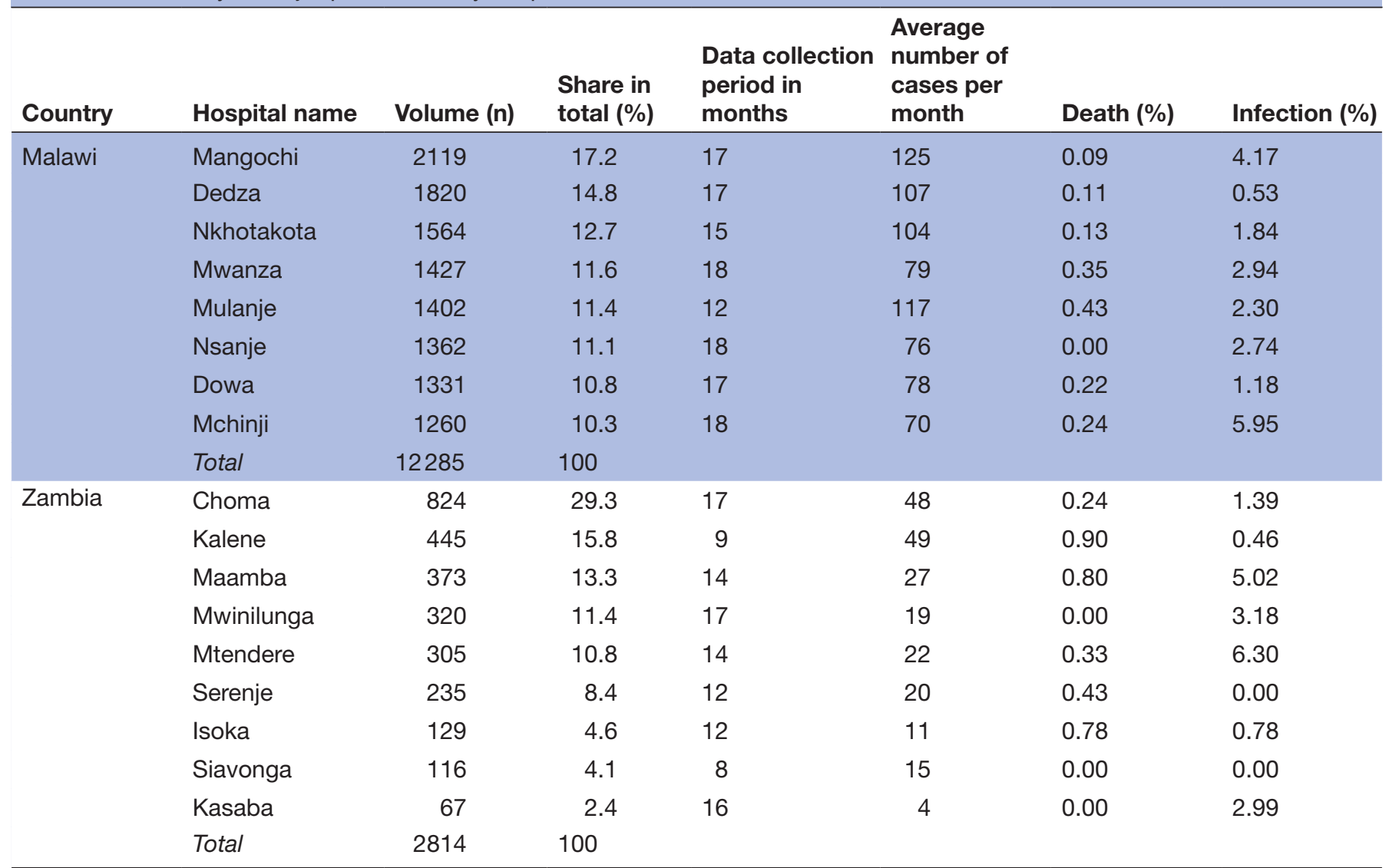

The monthly average number was calculated by the applicable months for which the data were available.

women aged 56-60 years, there were 12 gynaecological procedures, in which one patient died after operation and the other was infected after operation.

\section{Correlation estimation}

Surgical outcome estimates, based on logistic regression and penalised maximum likelihood estimation (PMLE), are presented in table 5. Although the mortality rate was quite low, the results of the two analyses were numerically close. The age of the patient was positively and significantly associated with perioperative mortality (PMLE $\mathrm{OR}=1.046,95 \%$ CI 1.021 to 1.076 ). An increase in age of 1 year was associated with a $4.6 \%$ increase in perioperative mortality rate. No significant difference was found between males and females. Compared with patients with ASA score I, patients with ASA scores II (PMLE OR=6.658, 95\% CI 2.363 to 18.762 ) and III-V (PMLE OR=46.74, 95\% CI 17.274 to 126.470 ) tended to have a higher probability of death. The mortality rate among general surgery patients was 3.821 times higher than for obstetric surgery (PMLE OR=3.821, 95\% CI 1.226 to 11.908 ). After correction of bias caused by rare observations of death by using penalised maximum likelihood logistic regression, emergency operations (PMLE OR=4.264, 95\% CI 1.283 to 14.167) were significantly more likely than elective cases to result in death. There was neither a significant association between mortality and the composition of the

Table 3 In-hospital perioperative mortality rates and postoperative infection rates by procedure and by country

\begin{tabular}{|c|c|c|c|c|c|c|}
\hline & \multicolumn{3}{|c|}{ Perioperative mortality } & \multicolumn{3}{|c|}{ Postoperative infection } \\
\hline & Full (\%) & Malawi (\%) & Zambia (\%) & Full (\%) & Malawi (\%) & $\begin{array}{l}\text { Zambia } \\
(\%)\end{array}$ \\
\hline Obstetric & 0.18 & 0.15 & 0.33 & 2.18 & 2.28 & 1.62 \\
\hline General & 0.53 & 0.37 & 0.97 & 2.94 & 2.33 & 4.82 \\
\hline
\end{tabular}




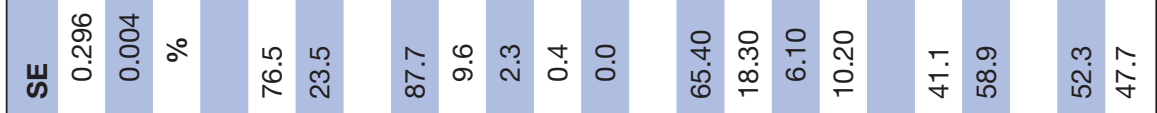

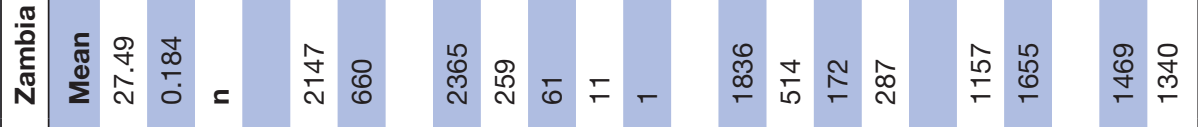

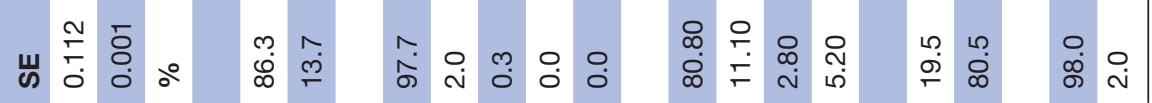

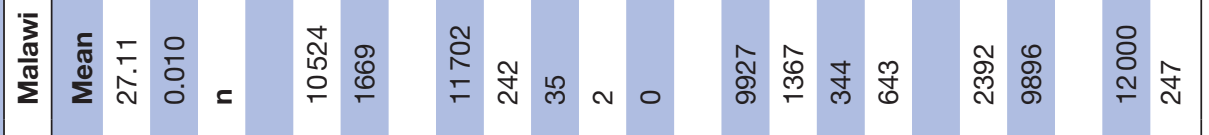

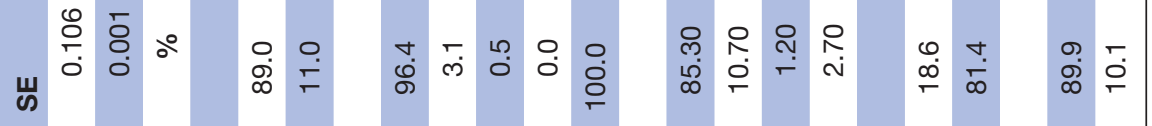

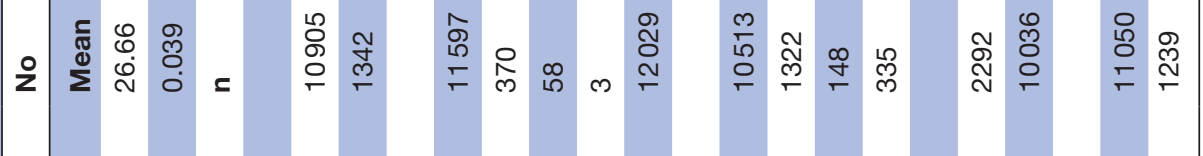

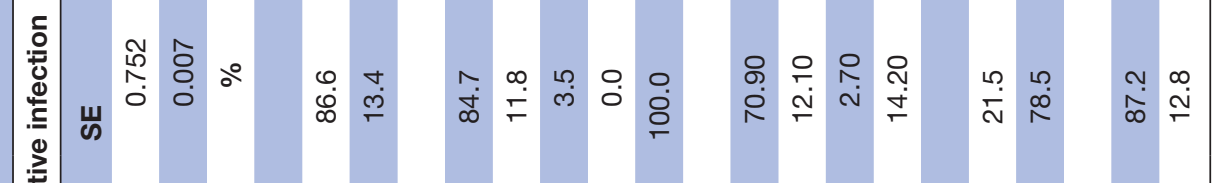

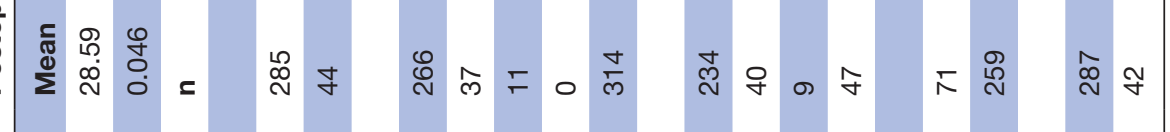

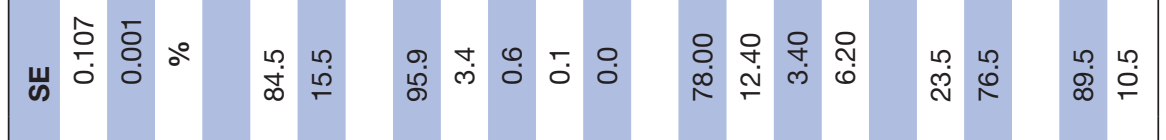

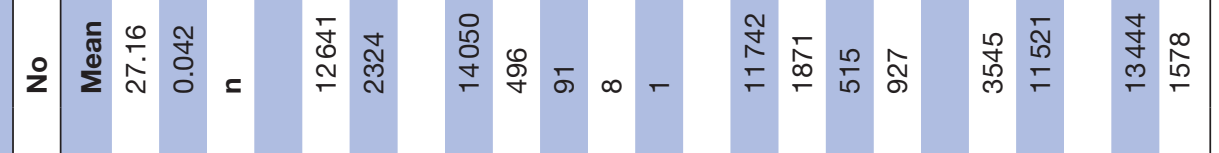

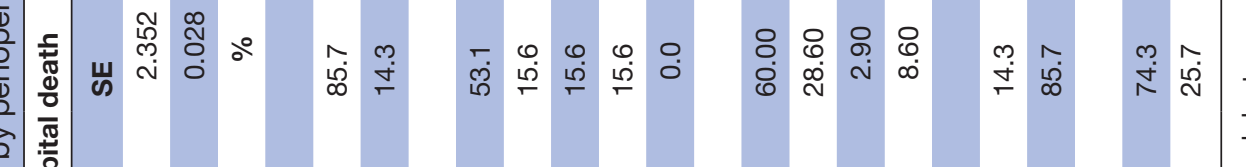

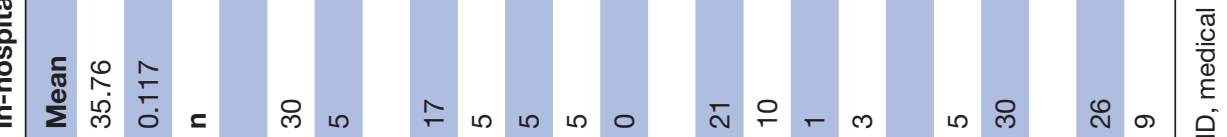
焉 $\frac{0}{2}$ 


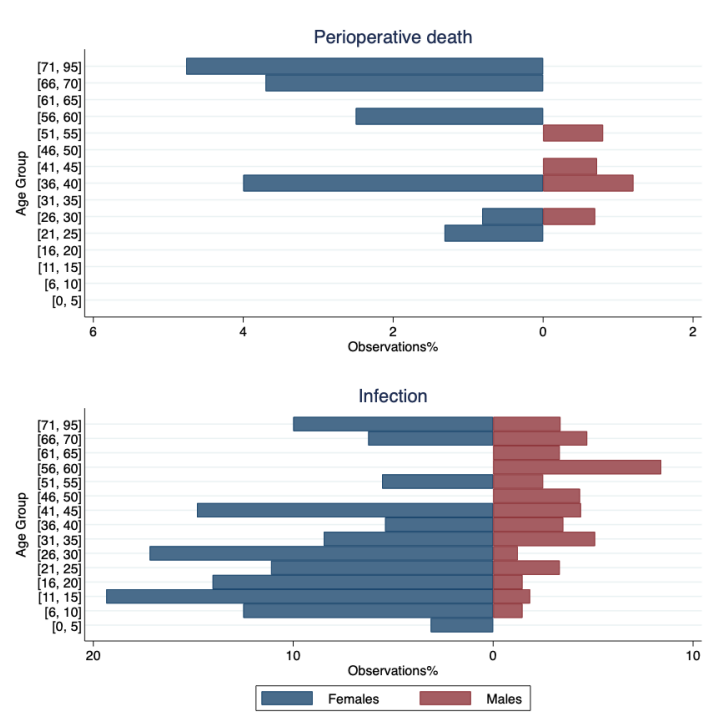

Figure 1 Number of perioperative deaths and postoperative infections by age and sex in general, trauma and other surgical procedures (excluding obstetric surgery). Navy, females; maroon, males.

surgical team, nor a significant difference in mortality between Malawi and Zambia.

As to the factors associated with the postoperative infection rate, an increase in age of 1 year is associated with $1.0 \%$ increase in the infection rate (PMLE OR $=1.010$, $95 \%$ CI 1.000 to 1.020$)$. The postoperative infection rate among men was significantly lower than women (PMLE $\mathrm{OR}=0.407,95 \%$ CI 0.260 to 0.637 ). Similar to the mortality rate, ASA scores greater than I were strongly associated with the infection rate. Patients who underwent general

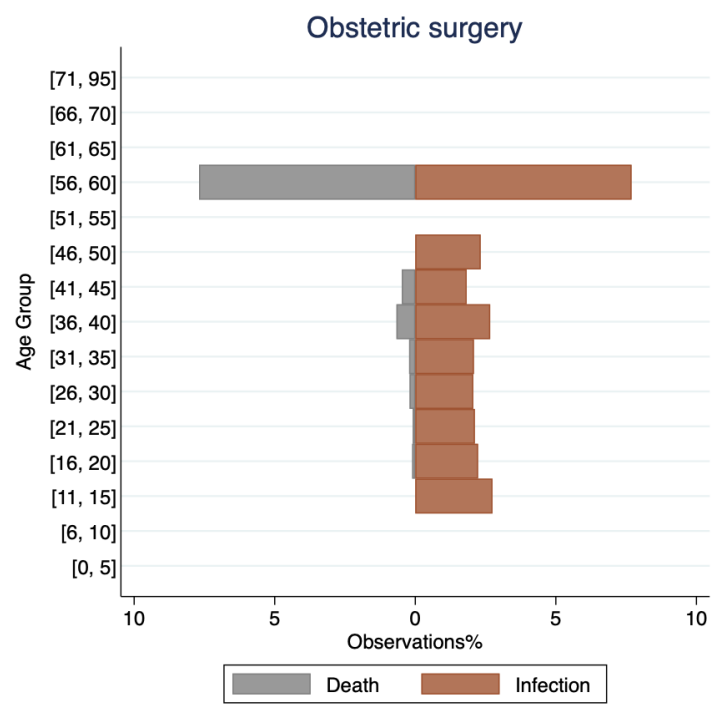

Figure 2 Number of perioperative deaths and postoperative infections in obstetric surgeries by age. Grey, death; sienna, infection. There was only one female patient in the 71-95 age group who had an infection after operation; this case is not presented on this graph for clarity.
(PMLE OR=2.319, 95\% CI 1.397 to 3.850), trauma-related (PMLE OR=5.490, 95\% CI 2.632 to 11.449) and other major procedures (PMLE OR=10.26, 95\% CI 6.687 to 15.742) were more likely to incur an infection postoperatively. There was no obvious difference in infection rates between emergency and elective surgery and no significant correlation with the composition of the surgical team. Zambia reported lower infection rates than Malawi (PMLE OR=0.432, 95\% CI 0.276 to 0.676 ).

\section{DISCUSSION}

Perioperative mortality is one of the six indicators proposed by the Lancet Commission on Global Surgery for monitoring progress towards universal access to safe, affordable surgical and anaesthesia care. ${ }^{11}$ Over the past 50 years, there has been a decline in anaesthesia-related procedure mortality in high Human Development Index $^{24} 25$ (HDI) countries. However low-HDI countries have shown no decline or even an increase in mortality rates, which highlights the importance of tackling perioperative mortality and other poor surgical outcomes in these settings. ${ }^{26}$ Recent systematic reviews reported that the overall incidence rate of SSI in SSA varied from $6.8 \%$ to $26 \%{ }^{18}$; and the average cumulative incidence rate of SSIs ranged from $2.5 \%$ to $30.9 \% .{ }^{19}$ However, little has been published about district-level perioperative mortality in rural SSA, which is the contribution of this study based on a sample of $17 \mathrm{DHs}$ in Malawi and Zambia.

The overall perioperative mortality rate and postoperative infection rate in this study were lower than in other studies in SSA countries. ${ }^{13} 14$ 27-29 Reasons may include, first, that this study focused only on district-level surgery, compared with other published studies on the subject which often include multiple levels of healthcare facilities. The types of procedures performed at district level, which in this study were mostly emergency obstetric, general and orthopaedic procedures, are technically less complex than procedures done at higher levels of care reported in other studies. ${ }^{13142729}$ The existing evidence indicated that the risk of infections and complications increased with the surgical complexity ${ }^{18}$ and the level of healthcare facilities. ${ }^{13}$ Second, a younger, healthier population accessed surgery at district level (mean age 27 years), compared with older and/or less healthy surgical patients who were usually referred to higher levels of care. The results in this study indicated that poorer surgical outcomes (deaths and infections) were significantly correlated with the older age patients' poorer physical status (higher ASA scores), and with general surgery procedures. There has been a considerable investment in SSA in reduction of maternal deaths, ${ }^{30}$ which can explain the difference in surgical outcomes for general surgery versus obstetric cases. A third and important potential reason is that the provision of surgical care at DHs, which are the first entry point for curative care for rural populations, reduces the need for referrals and associated risks, which may be beneficial for outcomes. On the contrary, patients at higher care levels 
Table 5 Logistic analysis of perioperative mortality and postoperative infection: ORs and 95\% Cl

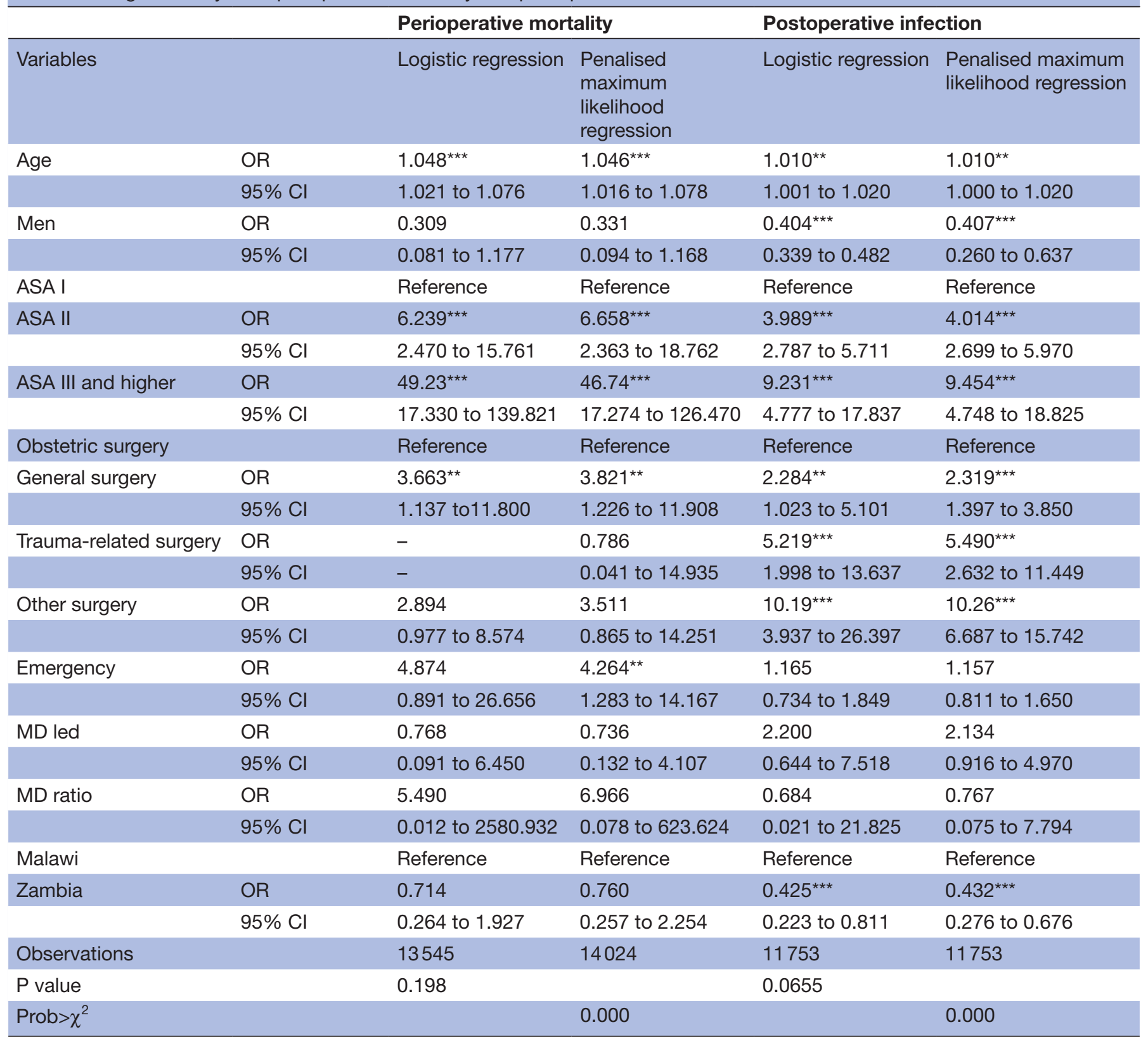

${ }^{* *} \mathrm{P}<0.05 ;{ }^{* *} \mathrm{p}<0.01$. There was no death reported in trauma-related surgery and it cannot predict the mortality probability perfectly. So the category was omitted. $\mathrm{X}^{2}$ test was used for testing the penalised maximum likelihood logistic regression.

ASA, American Society of Anesthesiologists; MD, medical doctor.

are often referred from lower care levels and during transfer, patients might deteriorate en route to a referral hospital, increasing the risk of poorer outcomes due to delayed surgical interventions.

A meta-analysis reviewing caesarean section (CS) outcomes indicated a higher incidence of SSIs when performed by clinical officers as opposed to physician surgical providers; this was interpreted as an indication of a need for enhanced training of clinical officers. ${ }^{8}$ The in-service training and supervision provided to NPCs in this study is a plausible reason why the obstetric SSI rate $^{31}$ and maternal death rate ${ }^{32}$ in our study were lower in comparison to previous SSA studies, which focused solely on CS and were likely to experience higher infection rates. Most operations in this study were conducted in facilities in which surgically trained NPCs are the main providers: clinical officers trained to BSc in Surgery level in Malawi, ${ }^{33}$ and medical licentiates, a form of an upgraded clinical officer with advanced clinical (including surgical) training, in Zambia. ${ }^{3}$ The absence of any significant difference in the quality of the surgical outcomes, including maternal and perinatal deaths, between surgical NPCs and doctors is consistent with previous studies. ${ }^{3021}$ The robust surgical training offered to NPCs in Malawi ${ }^{21}$ and $\mathrm{Zambia}^{3}$ could also explain the overall lower SSI and death rates compared with other 
studies. These results demonstrate that a selection of less complex types of surgery can be performed by surgically trained and supervised non-doctors (NPCs) working in DHs, achieving relatively good outcomes, which provides a model for the provision of surgical care to district and rural populations that may be applicable in other similar SSA countries. Non-specialist surgical providers can fill in an important gap as long as they receive adequate training.

\section{Limitation}

There are several limitations in this study. First, the data on SSI and surgical deaths were self-reported by staff from participating hospitals which might have led to underreporting. The SSI and death rates were similar across all 17 participating hospitals, though, suggesting that this bias might not have occurred. Second, selection bias and a Hawthorne effect may have been possible, in that the hospitals included in the analysis were participating in the COST-Africa surgical training programme, which offered surgical training to selected NPCs accompanied by periodic supervision. ${ }^{21} 21$ This may have resulted in an improved performance of these hospitals vis-à-vis other rural hospitals in delivering surgical services during the intervention period, limiting the generalisability of the findings. However, we did not observe a statistically different outcome between participating NPCs and other surgical staff offering surgical services in these facilities. Another limitation of this paper is a lack of assessment of complications in the long term, although the authors previously published a study of longer term outcomes from hernia repair surgery in Malawi. ${ }^{34}$

\section{Author affiliations}

${ }^{1}$ Institute of Global Surgery, Royal College of Surgeons in Ireland, Dublin, Ireland ${ }^{2}$ Department of Epidemiology and Public Health Medicine, Royal College of Surgeons in Ireland, Dublin, Ireland

${ }^{3}$ Department for Health Evidence, Radboud University Medical Center

(Radboudumc), Nijmegen, Netherlands

${ }^{4}$ Department of Surgery, University of Malawi College of Medicine, Blantyre, Southern Region, Malawi

${ }^{5}$ Department of Surgery, University Teaching Hospital, University of Zambia, Lusaka, Zambia

Contributors JG codesigned the study, collected and cleaned the data, drafted parts of the manuscript and reviewed the final version. MZ analysed the data and led the write-up of the manuscript. LB codesigned the study, and supported data interpretation, manuscript write-up and review. CP supported data interpretation, manuscript write-up and review. EB conceived and designed the study, led study implementation in Malawi and reviewed and interpreted the findings. GM facilitated data collection, codesigned the study and reviewed the manuscript. JK conceived and designed the study, led the study implementation in Zambia, reviewed and interpreted the findings, facilitated data collection and revived the manuscript. MC facilitated data collection, codesigned the study and revived the manuscript. KW collated the data and helped with data cleaning, conducted background literature review and wrote parts of the manuscript. RB obtained the funding, codesigned the study, supported data interpretation and oversaw manuscript write-up and review. $J G$ acts as the guarantor.

Funding This study was part of the SURG-Africa project, which is funded by the European Union's Horizon 2020 Programme for Research and Innovation under grant agreement number 733391 .

Competing interests None declared.
Patient and public involvement Patients and/or the public were not involved in the design, or conduct, or reporting, or dissemination plans of this research.

Patient consent for publication Not required.

Ethics approval The study was reviewed and approved by the University of Zambia Biomedical Research Ethics Committee (reference: 018-0312), the University of Malawi College of Medicine Research Ethics Committee (reference number: P.03/12/1188) and the Research Ethics Committee of the Royal College of Surgeons in Ireland (reference: REC727). Participants gave informed consent to participate in the study before taking part.

Provenance and peer review Not commissioned; externally peer reviewed.

Data availability statement Data are available upon reasonable request. Data are available on request from the lead author.

Open access This is an open access article distributed in accordance with the Creative Commons Attribution Non Commercial (CC BY-NC 4.0) license, which permits others to distribute, remix, adapt, build upon this work non-commercially, and license their derivative works on different terms, provided the original work is properly cited, appropriate credit is given, any changes made indicated, and the use is non-commercial. See: http://creativecommons.org/licenses/by-nc/4.0/.

\section{ORCID iDs}

Mengyang Zhang http://orcid.org/0000-0001-9865-8094

Leon Bijlmakers http://orcid.org/0000-0003-2252-0579

Chiara Pittalis http://orcid.org/0000-0003-3465-9850

\section{REFERENCES}

1 Juran S, Broer PN, Klug SJ, et al. Geospatial mapping of access to timely essential surgery in sub-Saharan Africa. BMJ Glob Health 2018;3:e000875.

2 Grimes CE, Law RSL, Borgstein ES, et al. Systematic review of Met and unmet need of surgical disease in rural sub-Saharan Africa. World J Surg 2012;36:8-23.

3 Gajewski J, Mweemba C, Cheelo M, et al. Non-Physician clinicians in rural Africa: lessons from the medical Licentiate programme in Zambia. Hum Resour Health 2017;15:1-9.

4 Gajewski J, Dharamshi R, Strader M, et al. Who accesses surgery at district level in sub-Saharan Africa? Evidence from Malawi and Zambia. Trop Med Int Health 2017;22:1533-41.

5 Federspiel F, Mukhopadhyay S, Milsom PJ, et al. Global surgical, obstetric, and anesthetic task shifting: a systematic literature review. Surgery 2018;164:553-8.

6 Matinhure S, Chimbari MJ. Barriers and enablers to task shifting for caesarean sections in sub-Saharan Africa: a scoping review. Afr J Reprod Health 2019;23:149-60.

7 Burton A. Training non-physicians as neurosurgeons in sub-Saharan Africa. Lancet Neurol 2017;16:684-5.

8 Wilson A, Lissauer D, Thangaratinam S, et al. A comparison of clinical officers with medical doctors on outcomes of caesarean section in the developing world: meta-analysis of controlled studies. BMJ 2011;342:d2600.

9 Nwanna-Nzewunwa OC, Ajiko M-M, Kirya F, et al. Barriers and facilitators of surgical care in rural Uganda: a mixed methods study. $J$ Surg Res 2016;204:242-50.

10 Chilopora G, Pereira C, Kamwendo F, et al. Postoperative outcome of caesarean sections and other major emergency obstetric surgery by clinical officers and medical officers in Malawi. Hum Resour Health 2007;5:17.

11 Meara JG, Leather AJM, Hagander L, et al. Global surgery 2030: evidence and solutions for achieving health, welfare, and economic development. The Lancet 2015;386:569-624.

12 Davies JF, Lenglet A, van Wijhe M, et al. Perioperative mortality: analysis of 3 years of operative data across 7 general surgical projects of Médecins sans Frontières in Democratic Republic of Congo, central African Republic, and South Sudan. Surgery 2016;159:1269-78.

13 Biccard BM, Madiba TE, Kluyts H-L, et al. Perioperative patient outcomes in the African surgical outcomes study: a 7-day prospective observational cohort study. Lancet 2018;391:1589-98.

14 GlobalSurg Collaborative. Surgical site infection after gastrointestinal surgery in high-income, middle-income, and low-income countries: a prospective, international, multicentre cohort study. Lancet Infect Dis 2018;18:516-25.

15 Allegranzi B, Bagheri Nejad S, Combescure C, et al. Burden of endemic health-care-associated infection in developing countries: systematic review and meta-analysis. Lancet 2011;377:228-41. 
16 Storr J, Twyman A, Zingg W, et al. Core components for effective infection prevention and control programmes: new who evidencebased recommendations. Antimicrob Resist Infect Control 2017;6:6.

17 Badia JM, Casey AL, Petrosillo N, et al. Impact of surgical site infection on healthcare costs and patient outcomes: a systematic review in six European countries. J Hosp Infect 2017;96:1-15.

18 Ngaroua N, Ngah JE, Bénet T, et al. Incidence des infections Du site opératoire en Afrique sub-saharienne: revue systématique et métaanalyse. Pan African Medical Journal 2016;24.

19 Bagheri Nejad S, Allegranzi B, Syed SB, et al. Health-careassociated infection in Africa: a systematic review. Bull World Health Organ 2011;89:757-65.

20 Gajewski J, Cheelo M, Bijlmakers L, et al. The contribution of Nonphysician clinicians to the provision of surgery in rural Zambia-a randomised controlled trial. Hum Resour Health 2019;17:60.

21 Gajewski J, Borgstein E, Bijlmakers L, et al. Evaluation of a surgical training programme for clinical officers in Malawi. Br J Surg 2019;106:e156-65.

22 Firth D. Bias reduction of maximum likelihood estimates. Biometrika 1993;80:27-38.

23 Heinze G, Schemper M. A solution to the problem of separation in logistic regression. Stat Med 2002;21:2409-19.

24 United Nations Development Programme. Human development report. New York: Oxford Unversity Press, 1990.

25 Ng-Kamstra JS, Arya S, Greenberg SLM, et al. Perioperative mortality rates in low-income and middle-income countries: a systematic review and meta-analysis. BMJ Glob Health 2018;3:e000810.
26 Bainbridge D, Martin J, Arango M, et al. Perioperative and anaesthetic-related mortality in developed and developing countries: a systematic review and meta-analysis. Lancet 2012;380:1075-81.

27 Pearse RM, Moreno RP, Bauer P, et al. Mortality after surgery in Europe: a 7 day cohort study. The Lancet 2012;380:1059-65.

28 Nkurunziza T, Kateera F, Sonderman K, et al. Prevalence and predictors of surgical-site infection after caesarean section at a rura district hospital in Rwanda. BJS 2019;106:e121-8.

29 Mezemir R, Seid A, Gishu T, et al. Prevalence and root causes of surgical site infections at an academic trauma and burn center in Ethiopia: a cross-sectional study. Patient Saf Surg 2020;14:3.

30 Serbanescu F, Goldberg HI, Danel I, et al. Rapid reduction of maternal mortality in Uganda and Zambia through the saving mothers, giving life initiative: results of year 1 evaluation. BMC Pregnancy Childbirth 2017;17:42.

31 Bishop D, Dyer RA, Maswime S, et al. Maternal and neonatal outcomes after caesarean delivery in the African surgical outcomes study: a 7-day prospective observational cohort study. Lancet Glob Health 2019;7:e513-22.

32 Fenton PM, Whitty C, Reynolds F. Caesarean section in Malawi: preventable factors in maternal and perinatal mortality. Malawi Med $J$ 2003;15:87

33 van Amelsfoort JJC, van Leeuwen PAM, Jiskoot $P$, et al. Surgery in Malawi--the training of clinical officers. Trop Doct 2010;40:74-6.

34 Gajewski J, Conroy R, Bijlmakers L, et al. Quality of surgery in Malawi: comparison of patient-reported outcomes after hernia surgery between district and central hospitals. World J Surg 2018;42:1610-6. 